\title{
Intragastric nitric oxide production in humans: measurements in expelled air
}

\author{
J O N Lundberg, E Weitzberg, J M Lundberg, K Alving
}

\begin{abstract}
High values ( $800-6000$ parts per billion) of nitric oxide (NO) in expelled air from the stomach were shown in humans by chemiluminescence technique. These NO values were more than 100 times higher than those found in orally exhaled air. Intragastric NO production is probably non-enzymatic, requiring an acidic environment, as NO in expelled air was reduced by $95 \%$ after pretreatment with the proton pump inhibitor omeprazole. Furthermore, large amounts of NO were formed in vitro from lettuce and saliva when placed in hydrogen chloride $(\mathrm{pH}<2)$. In conclusion, large amounts of NO are formed intragastrically in humans and this source of NO may be of importance for the integrity of the gastric mucosa in health and disease. Measurements of NO in expelled air might be of value as a non-invasive method for estimation of gastric acidity.

(Gut 1994; 35: 1543-1546)
\end{abstract}

Human saliva contains both nitrate and nitrite. ${ }^{1}$ Nitrate is absorbed in the gastrointestinal tract and extracted from plasma into saliva by the salivary glands. ${ }^{1}$ Most of the nitrite in saliva results from reduction of nitrate by a variety of micro-organisms in the oral cavity. ${ }^{1}$ Regularly swallowed saliva will continuously enter an acidic environment in the stomach, and under these conditions nitrite may be reduced to nitric oxide (NO). ${ }^{2}$ We wanted to investigate if $\mathrm{NO}$ is formed intragastrically in humans and to compare that with NO formation from saliva and nitrate containing food in an acidic environment in vitro. Furthermore, as increased values of NO have recently been shown in exhaled air of asthmatic subjects, ${ }^{3}$ we also wanted to examine if $\mathrm{NO}$ formation in the stomach would influence the values of NO in exhaled air. Parts of these results have been presented in a preliminary form. ${ }^{4}$

\section{Methods}

Anaesthesiology and Intensive Care, Karolinska Hospital, Stockholm, Sweden E Weitzberg

Correspondence to: Dr J O N Lundberg, Department of Physiology and Pharmacology, and Pharmacology, 77 Stockholm, Sweden.

Accepted for rapid publication 22 June 1994 subjects (30-40 years old), with confirmed allergy towards at least rat allergen, and symptoms of mild asthma and rhinitis took part in the study. One of the asthmatic subjects inhaled a glucocorticoid (budesonide) regularly and the other three inhaled a $\beta_{2}$ agonist or sodium cromoglycate when necessary. All subjects were tested when they were subjectively free from respiratory tract infections and none reported any symptoms of dyspepsia. The procedures used in this study have been reviewed and approved by the local ethical committee.

\section{NITRIC OXIDE VALUES IN EXPELLED AIR FROM} THE STOMACH

Voluntary regurgitation of air was performed three to five minutes after intake of $30 \mathrm{cl}$ of carbonated water with a pH of 5.5 (Ramlösa; Pripps AB, Sweden). Expelled air was led into a Teflon tubing system from which air was continuously sampled $(0.8 \mathrm{l} / \mathrm{min})$ into an NO chemiluminescence analyser (CLD 700; Eco Physics, Dürnten, Switzerland), and peak concentrations of NO were registered on a chart recorder. The detection limit for NO was 1 part per billion (ppb) and calibrations at known concentrations of $\mathrm{NO}$ in $\mathrm{N}_{2}$, using an electromagnetic flow controller (Environics Inc, Middletown CT, US) were performed. The chemiluminescence assay is highly specific for $\mathrm{NO}$ and does not interfere with other nitrogen oxides. ${ }^{2}$ Measurements of $\mathrm{NO}$ in expelled air from the stomach were made after 10 hours of fasting in combination with one of the following pretreatment procedures: (1) no pretreatment (control); (2) intake of $50 \mathrm{~g}$ of iceberg lettuce (nitrate load). The mean nitrate content in ordinary iceberg lettuce is $1.3 \mathrm{~g} / \mathrm{kg}^{5}$; (3) pretreatment by oral intake of a total of $240 \mathrm{mg}$ (three times $80 \mathrm{mg}$ ) of the proton pump inhibitor omeprazole (Astra-Hässle $\mathrm{AB}$, Göteborg, Sweden) distributed over a 24 hour period before the experiments; (4) intake of $50 \mathrm{~g}$ of lettuce after omeprazole pretreatment.

\section{NITRIC OXIDE FORMATION IN VITRO}

A glass bottle (1 litre) standing on a heat plate with a magnetic stirrer was used. The investigated test substances were placed in the glass bottle, which was then closed during an incubation time of five minutes. The substances used were: $30 \mathrm{cl}$ of carbonated water in $50 \mathrm{ml}$ of $\mathrm{HCl}(100 \mathrm{mM}, \mathrm{pH} 1 \cdot 0) ; 50 \mathrm{~g}$ of lettuce (cut in small pieces) in $50 \mathrm{ml} \mathrm{HCl}$ (100 mM, pH 1.0); 6-8 $\mathrm{g}$ of saliva in $50 \mathrm{ml}$ of $\mathrm{HCl}(100 \mathrm{mM}, \mathrm{pH} 1 \cdot 0)$, with and without $30 \mathrm{cl}$ of carbonated water; $2 \mathrm{~g}$ of saliva collected after 10 hours of fasting or two hours after intake of $250 \mathrm{~g}$ of lettuce, in $50 \mathrm{ml}$ of $\mathrm{HCl}$ (100 mM, pH 1.0); $50 \mathrm{~g}$ of chewed lettuce, containing $6-8 \mathrm{~g}$ of saliva in $50 \mathrm{ml}$ of different $\mathrm{HCl}$ solutions with $\mathrm{pH}$ ranging from 0.5 to $4 \cdot 0$ (316-0.1 mM) (saliva content was calculated 


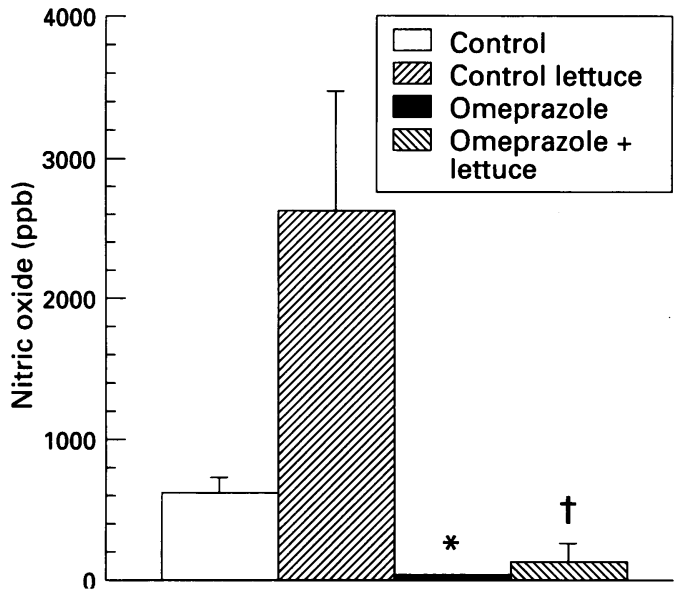

Figure 1: Peak NO values (ppb) in expelled air from the stomach. Regurgitation was performed after 10 hours of fasting, except for intake of $30 \mathrm{cl}$ of carbonated water five minutes before measurements. Control: no pretreatment. Control lettuce: intake of $50 \mathrm{~g}$ of iceberg lettuce five minutes before measurements. Omeprazole: pretreatment with $a$ total of $240 \mathrm{mg}$ omeprazole distributed over 24 hours before the experiment. Omeprazole+lettuce: intake of lettuce after pretreatment with omeprazole. Mean (SEM) values are presented $(n=6) .{ }^{\star} p<0.05$ compared with the control and $\dagger p<0.05$ compared with control lettuce (Wilcoxon's signed rank test).

from the weight gain of the lettuce after one minute of chewing); nitrite solution ( $7 \mathrm{~g}, 0.25$ $\mathrm{mM} \mathrm{KNO}_{2}$ ) in $50 \mathrm{ml}$ of different $\mathrm{HCL}$ solutions with $\mathrm{pH}$ ranging from 1.0 to 6.2 $\left(100-6 \cdot 3 \times 10^{-7}\right) \mathrm{mM}$; nitrate solutions $(7 \mathrm{~g}$, $0.5 \mathrm{mM}$ and $5 \mathrm{mM} \mathrm{KNO}_{3}$ ) in $50 \mathrm{ml} \mathrm{HCl}$ $(100 \mathrm{mM}, \mathrm{pH} \mathrm{1} \cdot 0)$. The nitrite/nitrate concentrations were chosen because they resemble the physiological concentrations found in saliva of non-fasting controls. ${ }^{6}$ After an incubation time of five minutes, air was sampled $(0.8 \mathrm{1} / \mathrm{min})$ from the gaseous phase in the bottle by a Teflon tube with the end placed $3 \mathrm{~cm}$ above the solutions, and peak NO concentrations were registered. Ambient air $(\mathrm{NO}<2 \mathrm{ppb})$ was simultaneously allowed into the glass bottle through a small opening at the top to avoid the build up of a negative pressure. All samples of saliva were collected according to the method of Kerr. ${ }^{7}$ All $\mathrm{HCl}$ solutions used in the study contained $0.9 \% \mathrm{NaCl}$ and was prewarmed to $37^{\circ} \mathrm{C}$.

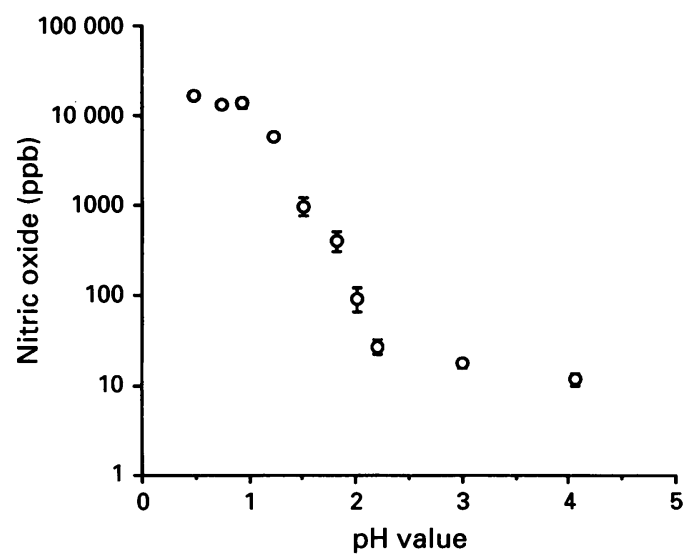

Figure 2: Peak NO values (ppb) in an in vitro experiment. Chewed lettuce (50 g, containing 6-8 g of saliva) in $50 \mathrm{ml}$ Chewed lettuce ( $\mathrm{HO} \mathrm{g}$, containing $6-8 \mathrm{~g}$ of saliva)
of different $\mathrm{pH}$ (range $0 \cdot 5-4 \cdot 0)$. Note the logarithmic scale on both the $y$ and $x$ axes. Missing error bars are obscured by the symbol $(n=4)$.
NITRIC OXIDE VALUES IN EXHALED AIR

The subjects wore a nose clip and breathed NO free air (NO <2 ppb; AGA AB, Lidingö, Sweden) with normal tidal volumes through a mouth piece connected to a non-rebreathing valve. Exhaled air was led into a Teflon tubing system from which air was continuously sampled $(0.8 \mathrm{1} / \mathrm{min})$, and steady state concentrations of NO during continuous breathing were recorded. NO measurements were made after 10 hours of fasting with and without omeprazole pretreatment.

\section{STATISTICS}

All data are presented as mean (SEM). Wilcoxon's signed rank test and MannWhitney $U$ test were used for paired and unpaired comparisons, respectively.

\section{Results}

NITRIC OXIDE VALUES IN EXPELLED AIR FROM THE STOMACH

Control NO concentrations in expelled air after 10 hours of fasting were 602 (107) ppb and these values increased fourfold, five minutes after intake of lettuce (Fig 1). Pretreatment with omeprazole considerably reduced the NO concentrations in expelled air both without $(96 \%)$ and with $(95 \%)$ intake of lettuce.

\section{NITRIC OXIDE FORMATION IN VITRO}

NO formation was strongly $\mathrm{pH}$ dependent between $\mathrm{pH} 1$ to 2 , when incubating chewed lettuce (containing 6-8 $\mathrm{g}$ of saliva) in $\mathrm{HCl}$ (Fig 2). The values at $\mathrm{pH} 1$ were 25 times higher than those formed from saliva alone in $\mathrm{HCl}$ and 500 times higher than from lettuce alone in $\mathrm{HCl}$. The addition of $30 \mathrm{cl}$ of carbonated water reduced NO formation by about $50 \%$ (Fig 3). Carbonated water alone in $\mathrm{HCl}$ did not produce any significant amounts of NO. In a separate experiment, saliva collected two hours after intake of $250 \mathrm{~g}$ of lettuce and placed in $\mathrm{HCl}$ ( $\mathrm{pH} 1.0$ ), yielded five times higher NO values than saliva collected after 10 hours of fasting (1640 (420) ppb and 334 (110) ppb respectively, $\mathrm{p}<0.05)$. NO formation was also $\mathrm{pH}$ dependent when incubating a nitrite solution in $\mathrm{HCl}$ at different $\mathrm{pH}$ (not shown). At $\mathrm{pH} 1 \cdot 0$, NO concentrations from the nitrite solution and saliva were similar (Fig 3). Nitrate solutions did not yield any NO when placed in $\mathrm{HCl}$ at $\mathrm{pH} 1.0$.

NITRIC OXIDE VALUES IN EXHALED AIR

Steady state values of NO in exhaled air were 4 (1) ppb and 14 (1) ppb in healthy subjects and asthmatic subjects, respectively. Omeprazole pretreatment did not significantly change these values.

\section{Discussion}

In this study we have identified the stomach as 


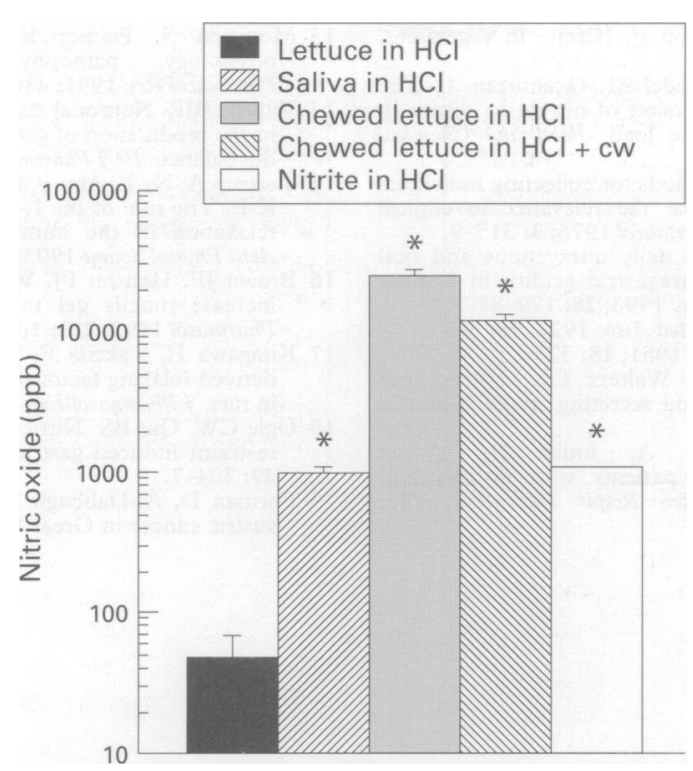

Figure 3: Peak NO values (ppb) in an in vitro experiment. Chequed lettuce $(50 \mathrm{~g})$ containing $6-8 \mathrm{~g}$ of saliva in $50 \mathrm{ml}$ of $\mathrm{HCl}(\mathrm{pH} \mathrm{1.0)}$ with and without $30 \mathrm{cl}$ of carbonated water (cw), and lettuce $(50 \mathrm{~g})$ or saliva $(6-8 \mathrm{~g})$ or nitrite solution $(7 \mathrm{~g}, 0.25 \mathrm{mM})$ alone in $50 \mathrm{ml}$ of $\mathrm{HCl}(\mathrm{pH} \mathrm{1.0})$. ${ }^{\star} p<0.05(n=5)$ compared with previous group

(Mann-Whitney U test).

an important source of $\mathrm{NO}$ at values greatly exceeding those in orally exhaled air. Intragastric NO formation seems to be dependent on an acidic environment, as inhibition of gastric acid secretion by the selective proton pump inhibitor omeprazole almost abolished NO in expelled air. Furthermore, lettuce and saliva in $\mathrm{HCl}$ in vitro, yielded high $\mathrm{NO}$ concentrations at $\mathrm{pH} 1$, with a gradual decrease at higher $\mathrm{pH}$. NO formation from chewed lettuce in $\mathrm{HCl}$ was $\mathrm{pH}$ dependent with very low concentrations of $\mathrm{NO}$ formed at a $\mathrm{pH}>3$, a $\mathrm{pH}$ probably obtained in the stomach in vivo after omeprazole pretreatment. ${ }^{8}$ The in vitro model with $50 \mathrm{ml}$ of $\mathrm{HCl}, \mathrm{pH} 1.0$ was chosen as this resembles the physiological situation regarding the amount ${ }^{9}$ and acidity ${ }^{10}$ of gastric juice during fasting conditions.

The substrate for intragastric NO formation is probably nitrite, as it is well known that nitrite is reduced in an acidic environment, thus forming NO. ${ }^{2}$ Gastric juice normally contains small but significant amounts of nitrite, ${ }^{11}$ which may be derived from swallowed saliva containing both nitrate and nitrite, ${ }^{1}$ or possibly from active gastric secretion of nitrite. ${ }^{11}$ Most of the nitrite in saliva is formed through the reduction of salivary nitrate by bacteria in the oral cavity. ${ }^{1}$ The daily saliva production in humans often exceeds one litre, thus permitting continuous formation of $\mathrm{NO}$ in the stomach over the day. These suggestions are supported by the fact that saliva alone in $\mathrm{HCl}$ in vitro yielded high amounts of NO, similar to those produced from a nitrite solution in $\mathrm{HCl}$. Furthermore, saliva collected after a nitrate load produced five times more NO compared with saliva collected after 10 hours of fasting when placed in $\mathrm{HCl}$. These results are in accordance with earlier studies showing that the nitrite concentration in saliva reaches a maximum two hours after a nitrate load. ${ }^{1}$ Intake of nitrate rich food (lettuce) increased the NO values in expelled air fourfold compared with fasting conditions. This could be explained by the high amounts of nitrate in lettuce ${ }^{5}$ being reduced to nitrite by bacterial enzymes in the saliva, which is also supported by the finding that chewed lettuce in $\mathrm{HCl}$ in vitro formed much more NO than saliva alone in $\mathrm{HCl}$. An alternative explanation may be that agents with reducing capacity in the lettuce could enhance nitrite formation from nitrate in the saliva.

As the stomach is anatomically related to the airways through the oesophagus, we also wanted to investigate its possible contribution to NO concentrations in exhaled air. The values of NO in expelled air after fasting were 100-1000 times higher than those in orally exhaled air. Hence, only minute amounts of expelled air may influence the exhaled values bearing in mind that asthmatic subjects may have a high incidence of gastro-oesophageal reflux. ${ }^{12}$ The high NO concentrations in the stomach, however, did not seem to contribute continuously to NO concentration in exhaled air during normal breathing in healthy subjects or asthmatic subjects, as these values were not affected by omeprazole pretreatment.

NO measurements in expelled air after a standard ingestion of nitrite could possibly be of clinical use, for example, in the diagnosis of achlorhydria and in monitoring of peptic ulcer disease, as it may reflect gastric acidity.

The finding that the stomach is an important source of NO is interesting, as NO may be important in bacteriostasis ${ }^{13}$ and in the regulation of mucosal blood flow, mucus formation, ${ }^{14}$ and possibly gastric motility including lower oesophageal sphincter tonus. ${ }^{15}$ Instillation of the NO donor isosorbide dinitrate into the rat gastric lumen in vivo produced an increase in mucus formation that was prevented by coadministration of oxyhaemoglobin, suggesting that the action was mediated by local release of NO. ${ }^{16}$ Furthermore, oral administration of nitrites in the rat prevents the formation of $\mathrm{HCl}$ induced gastric lesions, and topical application of nitrites to the gastric mucosa increases mucosal blood volume. ${ }^{17}$ Both these studies show that luminal NO may affect the gastric mucosa. The possible influence of the comparatively high amount of NO in the gastric lumen, even during fasting conditions, on the development of diseases such as peptic ulcer ${ }^{18}$ and stomach cancer ${ }^{19}$ needs further study.

This study was supported by grants from the Swedish Medical Research Council (project no 10162 and 10354), the Åke Wiberg Foundation, the Swedish Tobacco Company, the Magnus Bergwall Foundation, the Swedish Association Magnus Bergwall Foundation, the Swedish Association against Asthma and Allergy, the Konsul Th C Berg Diagnostics AB.

1 Tannenbaum SR, Weissman M, Fett B. The effect of nitrate intake on nitrite formation in human saliva. Food Cosmet intake on nitrite formation
Toxicol 1976; 14: 549-52.

2 Archer $S$. Measurement of nitric oxide in biological models. FASEB f 1993; 7: 349-60.

3 Alving K, Weitzberg E, Lundberg JM. Increased amounts of nitric oxide in exhaled air of asthmatics. Eur Respir $₹ 1993$ 6: 1368-70.

4 Lungberg J, Weitzberg E, Lundberg JM, Alving K. The stomach and the nasal airways as possible contributors to nitric oxide in exhaled air. American fournal of Respiratory and Critical Care Medicine 1994; 149: A462. 
5 Lönberg E, Everitt G, Mattson P. Nitrate in vegetables. Var Föda 1985; 37: 316-22.

6 Bos PMJ, Brandt PAVD, Wedel M, Ockhuizen T. The reproducibility of the conversion of nitrate to nitrite in human saliva after a nitrate load. Food and Chemical Toxicology 1988; 26: 93-7.

7 Stephen KW, Speirs CF. Methods for collecting individua components of mixed saliva: the relevance to clinical pharmacology. Br $\mathcal{F}$ Clin Pharmacol 1976; 3: 315-9.

8 Cederberg C. Effect of once daily intravenous and oral omeprazole on 24-hour intragastric acidity in healthy subjects. Scand $\mathcal{F}$ Gastroenterol 1993; 28: 179-84.

9 Rehfuss M, Hawk PB. 7 Am Med Assoc 1921; 76: 564.

10 Watkinson G. Gastroenterology 1951; 18: 377.

11 Ruddel WS. Blendis LM, Walters CL. Nitrite and thiocyanate in the fasting and secreting stomach and in saliva. Gut 1977; 18: 73-7.

12 Ducolone A, Vandevenne A, Jouin $\mathrm{H}$, et al. Gastroesophagal reflux in patients with asthma and chronic bronchitis. Am Rev Respir Dis 1987; 135: 327-32.
13 Moncada S, Palmer RMJ, Higgs EA. Nitric oxide: physiology, pathophysiology, and pharmacology. ;3: $109-41$.

14 Whittle BJR. Neuronal and endothelium-derived mediators in the modulation of gastric microcirculation: integrity in the balance. Br $\mathcal{F}$ Pharmacol 1993; 110: 3-17.

15 Tottrup A, Ny L, Alm P, Larsson B, Forman A, Andersson $\mathrm{K}-\mathrm{E}$. The role of the $\mathrm{L}$-arginine/nitric oxide pathway for relaxation of the human lower oesophagal sphincter. Acta Physiol Scand 1993; 149: 451-9.

16 Brown JF, Hanson PJ, Whittle BJR. Nitric oxide donors increase mucus gel thickness in rat stomach. Eur $\mathcal{f}$ Pharmacol 1992; 223: 103-4.

17 Kitagawa $\mathrm{H}$, Takeda $\mathrm{F}$, Kohei $\mathrm{H}$. Effect of endothelium derived relaxing factor on gastric lesion induced by $\mathrm{HCI}$ derived relaxing factor on gastric lesion induced

18 Ogle CW, Qiu BS. Nitric oxide inhibition intensifies coldrestraint induced gastric ulcers in rats. Experentia 1993; 49: 304-7.

19 Forman D, Al-Dabbagh S, Doll R. Nitrates, nitrites and gastric cancer in Great Britain. Nature 1985; 313: 620-5 